\title{
PEST MANAGEMENT
}

\section{Divergência Genética de Cultivares de Arroz quanto à Resistência a Tibraca limbativentris Stål (Hemiptera: Pentatomidae)}

\author{
Joseane R de Souza ${ }^{1}$, Evane Ferreira ${ }^{\dagger 2}$, Alberto Cargnelutti Filho ${ }^{3}$, Arlindo L Boiça Jr ${ }^{4}$, \\ Evandro F das Chagas 5 , Janaína M Mondego ${ }^{6}$ \\ ${ }^{I}$ Doutoranda em Agronomia - Produção Vegetal, Depto. de Fitossanidade, FCAV/UNESP, Via de Acesso Prof Paulo \\ Donato Castellane, s/n, 14884-900, Jaboticabal, SP; joseaneagro@yahoo.com.br \\ ${ }^{2}$ Ex-pesquisador (In memorian), Embrapa Arroz e Feijão/CNPAF, C. postal 179, 753756-000, \\ Santo Antônio de Goiás, GO \\ ${ }^{3}$ Depto de Fitotecnia, UFSM, Av Roraima, 1000,97105-900, Santa Maria, RS; cargnelutti@pq.cnpq.br \\ ${ }^{4}$ Depto de Fitossanidade, FCAV/UNESP, Via de Acesso Prof Paulo Donato Castellane, s/n, 14884-900, \\ Jaboticabal,SP; aboicajr@fcav.unesp.br \\ ${ }^{5}$ Depto de Fitotecnia e Fitossanidade, UEMA, C. postal 9, 65000-000, São Luís, MA; evandro@uema.br \\ ${ }^{6}$ Mestranda em Agronomia - Produção Vegetal, Depto. de Fitossanidade, FCAV/UNESP, Via de Acesso Prof Paulo \\ Donato Castellane, s/n, 14884-900,Jaboticabal,SP; janainamondego@yahoo.com.br
}

Edited by André L Lourenção - IAC

Neotropical Entomology 38(5):671-676 (2009)

Genetic Divergence of Rice Cultivars for Resistance to Tibraca limbativentris Stål (Hemiptera: Pentatomidae)

\begin{abstract}
The genetic divergence of sixteen rice cultivars regarding their resistance to the rice stem bug, Tibraca limbativentris Stål, was estimated by multivariate analysis techniques. The experiment was carried out in greenhouse, in randomized block design with eight replications. Eight plant resistance related traits were evaluated. Genetic divergence was evaluated by multivariate procedures: generalized Mahalanobis $\left(\mathrm{D}^{2}\right)$ distance, the Tocher's grouping optimization method and canonical variables. The most dissimilar cultivars were Bico Ganga and Marabá Branco, while Agulha and Branco Tardão were the most similar. Five clusters were formed by the Tocher's optimization method. Three canonic variables explained $88.5 \%$ of the observed variation. We concluded that the multivariate analysis techniques are suitable for analyzing the genetic divergence among rice cultivars, indicating Bico Ganga and Marabá Branco as the most promising for future breeding programs of resistance to the rice stem bug.
\end{abstract}

KEY WORDS: Plant breeding, rice stem bug, multivariate analysis

RESUMO - A divergência genética de 16 cultivares de arroz quanto à resistência ao percevejo-docolmo-do-arroz, Tibraca limbativentris Stål, foi avaliada por meio de técnicas de análise multivariada. $\mathrm{O}$ experimento foi conduzido em casa de vegetação, em delineamento experimental de blocos ao acaso, com oito repetições. $\mathrm{Na}$ avaliação foram considerados oito caracteres de resistência ao ataque do inseto. A divergência genética foi avaliada por procedimentos multivariados: distância generalizada de Mahalanobis $\left(\mathrm{D}^{2}\right)$, método de agrupamento de otimização de Tocher e técnica de variáveis canônicas. As cultivares mais dissimilares foram Bico Ganga e Marabá Branco, enquanto Agulha e Branco Tardão foram as mais similares. Foram formados cinco grupos pelo método de otimização de Tocher. As três primeiras variáveis canônicas explicaram 88,5\% da variabilidade total disponível. Conclui-se que as técnicas de análise multivariada são eficientes para a análise da divergência genética entre as cultivares de arroz, com destaque para Marabá Branco e Bico Ganga, consideradas as mais promissoras a serem utilizadas em futuros cruzamentos para melhoramento visando resistência ao percevejo-do-colmo-do-arroz.

PALAVRAS-CHAVE: Melhoramento de plantas, percevejo-do-colmo-do-arroz, análise multivariada

O Brasil é o nono produtor mundial de arroz, Oryza sativa, e, excluindo-se os países asiáticos, o maior produtor. A metade da população mundial tem o arroz como sua principal fonte de alimento. As médias de produção e consumo de arroz no Brasil nos últimos dez anos foram de, respectivamente, 10,3 e 11,6 milhões de toneladas (Ferreira et al 2005). A 
produção nacional da safra 2006/07 foi de 11.110,1 t em área de $2.966,5$ ha, com produtividade média de $3.745 \mathrm{~kg} /$ ha (Conab 2007).

Entre os principais fatores que afetam a produtividade da cultura, destaca-se a ocorrência de pragas. No Brasil, o percevejo-do-colmo-do-arroz, Tibraca limbativentris Stål, é a praga de maior expressão econômica e, em alguns anos, ocorre em altas infestações, provocando prejuízos em termos de produtividade de até 90\% (Ferreira et al 1997). Devido ao hábito alimentar, ocorre na base do colmo das plantas e nem sempre a infestação é percebida a tempo. Ataca o colmo das plantas com mais de 20 dias de idade, sendo seus danos caracterizados pela morte parcial ou total da parte central dos colmos, sintoma conhecido por "coração-morto" (Ferreira et al 1997).

Entre os métodos de controle para o percevejo-do-colmodo-arroz, o químico tem sido o mais utilizado; entretanto, sua utilização sem o devido conhecimento das técnicas de aplicação, tem ocasionado o controle insatisfatório da praga e contribuído para o aumento da poluição ambiental e dos custos de produção. A necessidade de alternativas para o controle químico, aliada à crescente cobrança da sociedade por métodos menos agressivos ao meio ambiente, estimula a busca de novos métodos para o controle do percevejo-docolmo-do-arroz.

Diante desse fato, é importante o desenvolvimento de cultivares resistentes a T. limbativentris, visando, principalmente, à redução dos custos operacionais e dos riscos de contaminação dos agroecossistemas mediante o uso abusivo de agroquímicos (Lara 1991). Assim, torna-se necessário o conhecimento de possíveis fontes de resistência do arroz ao inseto.

Poucos são os trabalhos sobre resistência de cultivares ao percevejo-do-colmo-do-arroz (Trujillo 1970, Ferreira et al 1986, Souza \& Rodrigues, não publ.). Ferreira et al (1997) relataram que ainda não foram desenvolvidas nem selecionadas cultivares com essa característica para fins comerciais, e que a seleção de arroz para resistência a $T$. limbativentris seria baseada principalmente em cultivares com alta capacidade de perfilhamento e com menor número de perfilhos danificados.

Além do conhecimento de fontes promissoras de resistência ao percevejo-do-colmo-do-arroz, outro fator importante no melhoramento visando à obtenção de cultivar resistente a esse inseto é a divergência genética. No estudo da divergência genética, o grau de dissimilaridade intra ou interespecífica, ou entre genótipos de uma população melhorada, pode ser estimado por meio de técnicas multivariadas, como: análise por componentes principais, variáveis canônicas e análise de agrupamento (Suinaga et al 2003). Análises multivariadas procuram discriminar os indivíduos geneticamente, permitindo agrupá-los de tal forma que exista homogeneidade dentro do grupo e heterogeneidade entre grupos (Pereira \& Cruz 2003).

Em programas de melhoramento é necessário que os genitores a serem cruzados tenham ampla dissimilaridade genética entre si e médias favoráveis para os caracteres alvo de melhoramento (Pereira \& Cruz 2003). Estudos de divergência genética com vistas à identificação de fontes de resistência a insetos foram realizados por Moreira et al (2005) e Suinaga et al (2003). Neste trabalho objetivou-se avaliar a divergência genética entre 16 cultivares de arroz por meio de técnicas de análise multivariadas, visando a detecção de resistência a $T$. limbativentris.

\section{Material e Métodos}

O experimento foi conduzido no período de dezembro de 2004 a abril de 2005 , em casa de vegetação, no município de Santo Antonio de Goiás, GO. Foram utilizadas 16 cultivares de arroz de sequeiro (Tabela 1), sendo 15 cultivares tradicionais (Fonseca et al 1982) mais a cultivar de arroz irrigado BR IRGA 409, utilizada como testemunha devido à sua suscetibilidade a T. limbativentris (Ferreira et al 1997). Inicialmente, as 15 cultivares tradicionais e a testemunha foram semeadas espaçadas a $40 \mathrm{~cm}$ entre si, adotando-se delineamento experimental de blocos ao acaso, com oito repetições. Vinte dias após a semeadura, as plantas de cada tratamento, incluindo a testemunha, foram isoladas em gaiolas, contadas e infestadas com dez ninfas de segundo ínstar por cova. O experimento foi encerrado aos 35 dias após a infestação, quando surgiram insetos adultos na cultivar testemunha. Os insetos foram coletados, acondicionados em sacos de papel e mantidos em congelador por $24 \mathrm{~h}$. Em seguida, foram submetidos à secagem em estufa a $50^{\circ} \mathrm{C}$ por $36 \mathrm{~h}$ e pesados em balança de precisão.

As características de resistência das cultivares avaliadas nesse experimento foram: número de insetos vivos por planta (NIV), massa seca individual (MSI) e massa seca total (MST), em mg, superfície corporal individual (SCI) e superfície corporal total (SCT) de T. limbativentris, em $\mathrm{mm}^{2}$, colmos emitidos após infestação (CEA), colmos normais (CN) e colmos danificados (CD).

A massa seca e a superfície corporal total foram obtidas pela divisão da massa seca total e superfície corporal total de cada parcela pelo número de insetos vivos. A superfície corporal foi medida colocando o inseto sobre papel milimetrado e anotando-se o comprimento e a largura. O número de colmos normais foi obtido da subtração dos colmos finais pelo número de colmos com o sintoma "coração-morto" visível mais colmos com "coração-morto" não-visível. O sintoma "coração-morto" não-visível foi detectado realizando um corte em todos os colmos das plantas de cada parcela para visualizar se a folha central encontravase morta em seu interior. Os colmos danificados foram obtidos por meio do somatório de colmos com "coraçãomorto" visível e não-visível.

As análises estatísticas, como análise de variância e teste de Scott Knott (Scott \& Knott 1974), para comparação de médias, cálculo da distância generalizada de Mahalanobis $\left(\mathrm{D}^{2}\right)$, agrupamento pelo método de otimização de Tocher e a análise de variáveis canônicas, foram realizadas utilizando-se o programa computacional GENES (Cruz 2001).

\section{Resultados e Discussão}

$\mathrm{O}$ efeito das cultivares foi significativo $(\mathrm{P} \leq 0,05) \mathrm{em}$ relação aos caracteres número de insetos vivos (NIV), colmos 
Tabela 1 Análise de variância e teste de Scott \& Knott das características número de insetos vivos por planta (NIV), massa seca individual (MSI) e massa seca total (MST), por mg, superfície corporal individual (SCI) e superfície corporal total (SCT), por $\mathrm{mm}^{2}$, colmos emitidos após infestação (CEA), colmos normais (CN) e colmos danificados (CD) de 16 cultivares de arroz utilizadas para estudo de divergência genética por meio de técnicas multivariadas visando detectar resistência a Tibraca limbativentris.

\begin{tabular}{lcccccccc}
\hline \multirow{2}{*}{ Fonte de variação } & \multicolumn{8}{c}{ Quadrado médio } \\
\cline { 2 - 9 } & NIV & MSI & MST & SCI & SCT & CEA & CN & CD \\
\hline Tratamento & $22,321^{*}$ & $37,486^{\text {ns }}$ & $4246,059^{\text {ns }}$ & $19924,383^{\text {ns }}$ & $129,436^{\text {ns }}$ & $203,497^{*}$ & $5,148^{*}$ & $343,91^{*}$ \\
Cultivar & $4,128^{*}$ & $39,641^{\text {ns }}$ & $4371,354^{\text {ns }}$ & $20757,067^{\text {ns }}$ & $135,982^{\text {ns }}$ & $217,325^{*}$ & $5,515^{*}$ & $351,27^{*}$ \\
Cultivar vs testemunha & $1,2^{\text {ns }}$ & $7,314^{\text {ns }}$ & $2491,927^{\text {ns }}$ & $8266,8^{\text {ns }}$ & $37,800^{\text {ns }}$ & $9,918^{\text {ns }}$ & $0,015^{\text {ns }}$ & $240,83^{*}$ \\
Resíduo & 2,178 & 108,082 & 6403,894 & 13852,67 & 115,348 & 47,455 & 1,170 & 29,494 \\
\hline Média & 5,75 & 39,42 & 204,75 & 335,0 & 62,65 & 11,54 & 2,37 & 17,06 \\
CV (\%) & 25,66 & 26,37 & 38,08 & 35,13 & 17,14 & 59,65 & 45,56 & 31,82 \\
\hline
\end{tabular}

Cultivar

\begin{tabular}{lcccccccc}
\hline 1 - Arroz Misturado & $5,25 \mathrm{~b}$ & 40,88 & 190,01 & 255,00 & 54,84 & $5,37 \mathrm{c}$ & $1,34 \mathrm{c}$ & $9,37 \mathrm{~b}$ \\
2 - Agulha & $5,12 \mathrm{~b}$ & 40,06 & 185,21 & 318,00 & 65,63 & $3,75 \mathrm{c}$ & $1,23 \mathrm{c}$ & $7,87 \mathrm{~b}$ \\
3 - Arroz Comum & $5,25 \mathrm{~b}$ & 39,39 & 185,67 & 320,25 & 65,96 & $7,62 \mathrm{c}$ & $1,83 \mathrm{c}$ & $9,00 \mathrm{~b}$ \\
4 - Branco Tardão & $5,50 \mathrm{~b}$ & 39,32 & 189,41 & 330,37 & 65,95 & $5,37 \mathrm{c}$ & $1,45 \mathrm{c}$ & $8,00 \mathrm{~b}$ \\
5 - Bico Ganga & $6,75 \mathrm{a}$ & 34,37 & 202,17 & 391,75 & 62,71 & $14,37 \mathrm{a}$ & $3,23 \mathrm{a}$ & $11,37 \mathrm{~b}$ \\
6 - Come Cru Vermelho & $5,25 \mathrm{~b}$ & 40,81 & 189,56 & 303,75 & 63,69 & $11,75 \mathrm{~b}$ & $2,62 \mathrm{~b}$ & $11,37 \mathrm{~b}$ \\
7 - Cutião & $6,00 \mathrm{a}$ & 41,89 & 243,93 & 397,75 & 68,05 & $9,37 \mathrm{~b}$ & $2,11 \mathrm{c}$ & $17,87 \mathrm{a}$ \\
8 - Desconhecido Branco & $4,62 \mathrm{~b}$ & 38,48 & 173,88 & 249,87 & 55,93 & $9,50 \mathrm{~b}$ & $1,48 \mathrm{c}$ & $17,12 \mathrm{a}$ \\
9 - Gojoba Ligeiro & $6,00 \mathrm{a}$ & 37,28 & 204,85 & 334,50 & 61,42 & $19,12 \mathrm{a}$ & $3,56 \mathrm{a}$ & $23,12 \mathrm{a}$ \\
10 - Marabá Branco & $4,87 \mathrm{~b}$ & 40,76 & 184,46 & 265,50 & 57,69 & $23,00 \mathrm{a}$ & $3,88 \mathrm{a}$ & $28,25 \mathrm{a}$ \\
11 - Nenenzinho & $6,75 \mathrm{a}$ & 36,09 & 214,23 & 370,25 & 61,65 & $11,62 \mathrm{~b}$ & $2,13 \mathrm{c}$ & $21,25 \mathrm{a}$ \\
12 - Pingo D'agua & $6,50 \mathrm{a}$ & 40,28 & 239,76 & 391,25 & 65,56 & $15,87 \mathrm{a}$ & $3,19 \mathrm{a}$ & $22,00 \mathrm{a}$ \\
13 - Taboca & $5,25 \mathrm{~b}$ & 42,54 & 195,70 & 321,12 & 67,84 & $10,25 \mathrm{~b}$ & $2,32 \mathrm{c}$ & $20,87 \mathrm{a}$ \\
14 - Vermelho & $6,75 \mathrm{a}$ & 40,57 & 248,71 & 402,87 & 64,59 & $12,62 \mathrm{~b}$ & $2,56 \mathrm{~b}$ & $22,50 \mathrm{a}$ \\
15 - Vermelho Agulha & $6,00 \mathrm{a}$ & 37,65 & 206,58 & 341,62 & 60,41 & $12,50 \mathrm{~b}$ & $2,57 \mathrm{~b}$ & $20,62 \mathrm{a}$ \\
16 - BR IRGA 409 & $6,12 \mathrm{a}$ & 40,34 & 221,84 & 366,12 & 60,55 & $12,62 \mathrm{~b}$ & $2,41 \mathrm{~b}$ & $22,37 \mathrm{a}$ \\
\hline
\end{tabular}

* = significativo; $^{\text {ns }}=$ não significativo pelo teste de Scott Knott a 5\% de probabilidade. Médias não seguidas de mesma letra nas colunas diferem entre si pelo teste Scott Knott a 5\% de significância.

emitidos após infestação (CEA), colmos normais $(\mathrm{CN})$ e colmos danificados (CD), evidenciando a ocorrência de variabilidade genética (Tabela 1). As médias das cultivares pelo teste de Scott Knott, a 5\% de significância, em relação a esses caracteres, foram separadas em dois grupos para os caracteres número de insetos vivos por planta (NIV), colmos normais $(\mathrm{CN})$, colmos danificados $(\mathrm{CD})$, e em três grupos para o caráter colmos emitidos após infestação (CEA). Para os demais caracteres, massa seca total (MST) e individual (MSI), superfície corporal total (SCT) e individual (SCI) de T. limbativentris, não houve diferença significativa $(\mathrm{P}>0,05)$, evidenciando desempenho similar das cultivares.

As cultivares mais favoráveis à sobrevivência dos insetos foram Vermelho, Nenenzinho, Bico Ganga, Pingo D'água, Vermelho Agulha, Gojoba Ligeiro, Cutião e a testemunha (BR IRGA 409), que formaram um único grupo pelo teste de Scott Knott. Em outro grupo, encontram-se as cultivares Branco Tardão, Taboca, Come Cru Vermelho, Arroz Comum, Arroz Misturado, Agulha, Marabá Branco e Desconhecido Branco, com menor número de insetos vivos, indicando que são menos favoráveis à sobrevivência do inseto, provavelmente devido ao efeito antibiótico dessas cultivares sobre a biologia do inseto (Tabela 1).

Com relação ao número de colmos emitidos após a infestação (CEA) e colmos normais $(\mathrm{CN})$, observou-se que as cultivares Marabá Branco, Gojoba Ligeiro, Pingo D’água e Bico Ganga foram as que mais perfilharam após a infestação e apresentaram maior número de colmos normais ao término do experimento. As demais cultivares e a testemunha (BR IRGA 409) perfilharam menos e apresentaram menor número de colmos normais. Por outro lado, as cultivares Marabá Branco, Gojoba Ligeiro e Pingo D'água encontram-se no 
grupo com maior número de colmos danificados $(\mathrm{CD})$, porém sem diferir da testemunha. De acordo com Ferreira et al (1986), a tendência para maior número de colmos danificados está associada não só a aspectos genéticos da resistência, mas também a aspectos ambientais, pois no interior de plantas com maior quantidade de perfilhos, as condições microclimáticas (principalmente de umidade) seriam mais favoráveis ao crescimento da população do inseto.

Merecem especial atenção as cultivares Marabá Branco e Bico Ganga. Marabá Branco apresentou menor número de insetos vivos (NIV), maior quantidade de colmos emitidos após infestação (CEA) e de colmos normais (CN), características favoráveis e indicativas da presença de resistência do tipo antibiose e do tipo tolerância ao percevejodo-colmo-do-arroz, respectivamente (Tabela 1). A cultivar Bico Ganga apresentou maior número de insetos vivos (NIV), indicando que não causou nenhum efeito adverso na biologia dos mesmos, mas apresentou maior quantidade de colmos emitidos após infestação (CEA) e de colmos normais $(\mathrm{CN})$ e pequena quantidade de colmos danificados (CD). Esses resultados indicam que a resistência dessas cultivares de arroz pode estar associada à sua capacidade de perfilhamento e ao efeito antibiótico sobre a biologia do inseto. $\mathrm{O}$ desempenho de ambas as cultivares frente ao ataque do inseto é, segundo Lara (1991), um indicativo de que possivelmente sejam portadoras de resistência do tipo tolerância e do tipo antibiose a $T$. limbativentris. Segundo Ferreira et al (1986), que estudaram a possibilidade de identificar fontes de resistência de arroz ao percevejo-docolmo-do-arroz, é preferível selecionar cultivares e linhagens altamente perfilhadoras e com a quantidade mais baixa possível de colmos danificados.

As medidas de dissimilaridade genética estimadas pela distância generalizada de Mahalanobis $\left(\mathrm{D}^{2}\right)$ entre as 16 cultivares de arroz (Tabela 2) apontaram as cultivares Bico Ganga e Marabá Branco como as mais dissimilares $(16,70)$ e Agulha e Branco Tardão como as mais similares $(0,19)$.

A identificação de genitores com máxima divergência genética tem sido estudada em programas de melhoramento (Suinaga et al 2003, Moreira et al 2005) de modo a maximizar a heterose manifestada nos híbridos e aumentar a probabilidade de ocorrência de genótipos superiores nas gerações segregantes (Cruz \& Regazzi 1997). Outro fato importante que deve ser considerado na escolha dos genitores é se os mesmos pertencem a grupos diferentes, evitando-se o cruzamento entre genitores de mesmo agrupamento (Moreira et al 2005).

A análise de agrupamento pelo método de otimização de Tocher permitiu a formação de cinco grupos, sendo o grupo I formado pelas cultivares 2, 4, 3, 6 e 1; o grupo II pelas cultivares $9,12,15,11,14,7,13$ e 16 ; e os grupos III, IV e V pelas cultivares 10,8 e 5 , respectivamente (Tabela 3).

As três primeiras variáveis canônicas explicaram 88,5\% da variabilidade total disponível (Fig 1). A distribuição

Tabela 2 Medidas de dissimilaridade entre pares de cultivares de arroz em relação às características: número de insetos vivos por planta (NIV), massa seca individual (MSI) e massa seca total (MST), em mg, superfície corporal individual (SCI) e superfície corporal total (SCT) de Tibraca limbativentris, em $\mathrm{mm}^{2}$, colmos emitidos após infestação (CEA), colmos normais $(\mathrm{CN})$ e colmos danificados $(\mathrm{CD})$, com base na distância generalizada de Mahalanobis $\left(\mathrm{D}^{2}\right)$.

\begin{tabular}{|c|c|c|c|c|c|c|c|c|c|c|c|c|c|c|c|}
\hline Cultivar $^{1}$ & 2 & 3 & 4 & 5 & 6 & 7 & 8 & 9 & 10 & 11 & 12 & 13 & 14 & 15 & 16 \\
\hline 1 & 2,31 & 2,15 & 2,02 & 7,95 & 2,57 & 8,03 & 3,86 & 9,30 & 14,40 & 9,06 & 10,35 & 11,74 & 12,11 & 7,99 & 12,39 \\
\hline 2 & & 0,60 & 0,32 & 6,08 & 2,11 & 5,98 & 5,17 & 10,37 & 15,59 & 9,45 & 10,02 & 9,69 & 11,61 & 7,67 & 1,05 \\
\hline 3 & & & 0,19 & 3,93 & 0,69 & 6,68 & 5,77 & 8,72 & 14,61 & 9,69 & 9,24 & 11,00 & 12,01 & 7,96 & 11,86 \\
\hline 4 & & & & 4,59 & 1,40 & 6,81 & 5,89 & 9,79 & 16,07 & 9,42 & 9,89 & 11,05 & 12,07 & 8,21 & 11,84 \\
\hline 5 & & & & & 2,63 & 10,81 & 13,89 & 9,39 & 16,70 & 12,95 & 10,04 & 16,03 & 14,30 & 10,50 & 14,11 \\
\hline 6 & & & & & & 6,58 & 6,45 & 6,39 & 11,81 & 9,408 & 7,40 & 1,06 & 10,92 & 6,99 & 1,12 \\
\hline 7 & & & & & & & 4,46 & 3,155 & 5,29 & 2,16 & 1,56 & 1,30 & 1,42 & 0,89 & 2,09 \\
\hline 8 & & & & & & & & 6,23 & 6,82 & 4,97 & 7,11 & 6,45 & 7,21 & 4,33 & 6,35 \\
\hline 9 & & & & & & & & & 2,35 & 2,63 & 0,71 & 4,30 & 2,48 & 1,61 & 4,85 \\
\hline 10 & & & & & & & & & & 5,36 & 3,24 & 5,04 & 4,17 & 3,29 & 4,10 \\
\hline 11 & & & & & & & & & & & 1,79 & 2,67 & 0,98 & 1,10 & 2,89 \\
\hline 12 & & & & & & & & & & & & 2,48 & 0,82 & 0,86 & 3,05 \\
\hline 13 & & & & & & & & & & & & & 1,48 & 1,36 & 2,23 \\
\hline 14 & & & & & & & & & & & & & & 0,80 & 1,79 \\
\hline 15 & & & & & & & & & & & & & & & 1,48 \\
\hline
\end{tabular}

$\mathrm{D}^{2}$ máximo = 16,70 (cultivares 5 e 10 - Bico Ganga e Marabá Branco) - mais dissimilares; $\mathrm{D}^{2}$ mínimo = 0,19 (cultivares 3 e 4 - Agulha e Branco Tardão) - mais similares. Cultivares: 1) Arroz Misturado; 2) Agulha; 3) Arroz Comum; 4) Branco Tardão; 5) Bico Ganga; 6) Come Cru Vermelho; 7) Cutião; 8) Desconhecido Branco; 9) Gojoba Ligeiro; 10) Marabá Branco; 11) Nenenzinho; 12) Pingo D’água; 13) Taboca; 14) Vermelho; 15) Vermelho Agulha e 16) BR IRGA 409. 
Tabela 3 Agrupamento pelo método de otimização de Tocher de 16 cultivares de arroz com base na dissimilaridade expressa pela distância generalizada de Mahalanobis, estimada a partir de oito características ${ }^{1}$.

\begin{tabular}{ccl}
\hline Grupo & Número de cultivares & Cultivar $^{2}$ \\
\hline I & 5 & $2,4,3,6$ e 1 \\
II & 8 & $9,12,15,11,14,7,13$ e 16 \\
III & 1 & 10 \\
IV & 1 & 8 \\
V & 1 & 5 \\
\hline
\end{tabular}

${ }^{1}$ Número de insetos vivos por planta (NIV); massa seca individual (MSI) e massa seca total (MST) por mg; superfície corporal individual (SCI) e superfície corporal total (SCT) por $\mathrm{mm}^{2}$; colmos emitidos após infestação (CEA); colmos normais $(\mathrm{CN})$ e colmos danificados (CD).

${ }^{2}$ Cultivares: 1) Arroz Misturado; 2) Agulha; 3) Arroz Comum; 4) Branco Tardão; 5) Bico Ganga; 6) Come Cru Vermelho; 7) Cutião; 8) Desconhecido Branco;9) Gojoba Ligeiro; 10) Marabá Branco; 11) Nenenzinho; 12) Pingo D’água; 13) Taboca; 14) Vermelho; 15) Vermelho Agulha e 16) BR IRGA 409.

das cultivares no gráfico de dispersão permitiu identificar as cultivares 5,8 e 10 como as mais divergentes. Os resultados dessa análise permitem fazer inferências sobre o comportamento das cultivares em estudo, o que constitui informação útil na determinação do número de grupos na análise de agrupamento. A dispersão gráfica dos escores das três variáveis canônicas mostra boa concordância com

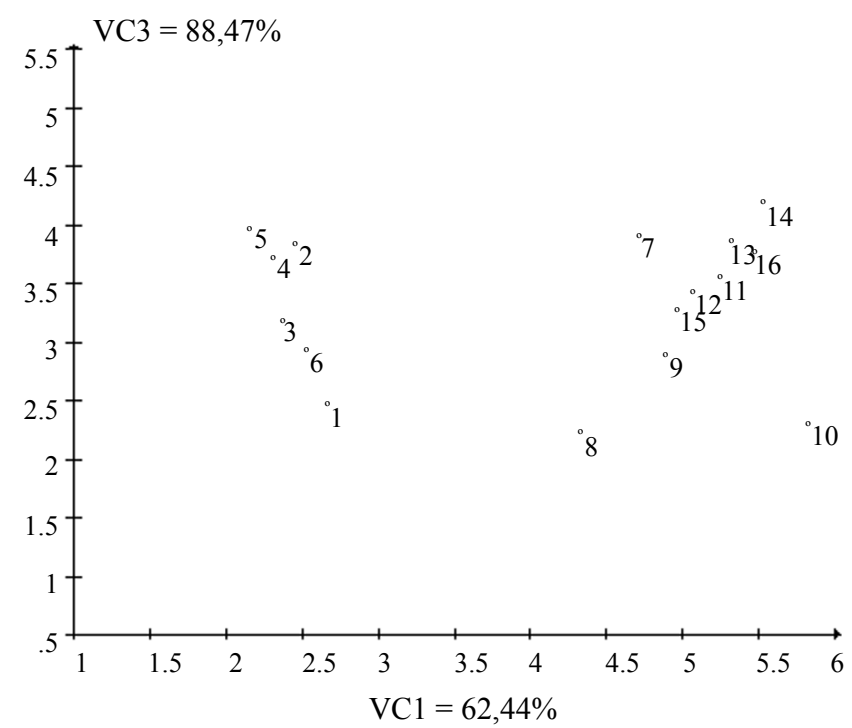

Fig 1 Dispersão dos escores de 16 cultivares de arroz em relação às três primeiras variáveis canônicas (VC1 e VC3) e variância acumulada (\%) tendo como base oito características de resistência de arroz a Tibraca limbativentris. Cultivares: 1 $=$ Arroz Misturado, $2=$ Agulha, $3=$ Arroz Comum, $4=$ Branco Tardão, 5 = Bico Ganga, $6=$ Come Cru Vermelho, $7=$ Cutião, 8 = Desconhecido Branco, $9=$ Gojoba Ligeiro, $10=$ Marabá Branco, 11 = Nenenzinho, 12 = Pingo D'água, 13 = Taboca, 14 $=$ Vermelho, $15=$ Vermelho Agulha e 16 = BR IRGA 409. o método de otimização de Tocher, permitindo identificar as cultivares 5, 8 e 10 como as mais divergentes em relação aos demais.

Em programas de melhoramento de arroz que visem resistência a $T$. limbativentris, devem ser preferidas cultivares com menor número de insetos por planta (NIV), menor massa seca total (MST) e individual (MSI) e menor superfície corporal total (SCT) e individual (SCI), maior quantidade de colmos normais e emitidos após infestação e menor número de colmos danificados (Lara 1991, Ferreira et al 1997).

Conclui-se que as técnicas de análise multivariadas são eficientes para a análise da divergência genética entre as cultivares de arroz. Com o uso dessas técnicas, podem ser consideradas as cultivares Marabá Branco e Bico Ganga como as mais promissoras a serem utilizados em futuros cruzamentos para melhoramento visando resistência ao percevejo-do-colmo-do-arroz.

\section{Agradecimentos}

Ao Centro Nacional de Pesquisa de Arroz e Feijãol EMBRAPA, pela oportunidade do estágio e ao ilustre Dr. Evane Ferreira (in memoriam) que com compreensão e humildade contribuiu para a conclusão desta pesquisa.

\section{Referências}

Companhia Nacional de Abastecimento (2007) Avaliação da safra agrícola 2006/2007- Quarto levantamento - janeiro/2007. http:// www.conab.gov.br/conabweb/dowload/safra/4levsafra.pdf. Acessado em: 23/08/07.

Cruz C D (2001) Programa genes: versão Windows. Aplicativo computacional em genética e melhoramento. Viçosa, UFV, $648 \mathrm{p}$.

Cruz C D, Regazzi A J (1997) Modelos biométricos aplicados ao melhoramento genético. 2.ed. Viçosa, Universidade Federal de Viçosa, 390p.

Ferreira C M, Sousa I S F, Méndez Del Villar P (2005) Desenvolvimento tecnológico e dinâmica da produção de terras altas no Brasil. Santo Antônio de Goiás, EMBRAPA - Arroz e Feijão, 118p.

Ferreira E, Martins J F S, Rangel P H N, Cutrim V A (1986) Resistência de arroz ao percevejo do colmo. Pesq Agropec Bras 21: 565-569.

Ferreira E, Zimmermann F J D, Santos A B, Neves B P (1997) O percevejo do colmo na cultura do arroz. Goiânia, EMBRAPA - Arroz e Feijão, 43p.

Fonseca J R, Rangel P H, Bedendo I P, Silveira P M, Guimarães E P, Corandin L (1982) Características botânicas e agronômicas de cultivares e raças regionais de arroz (Oryza sativa L.) coletadas no estado do Maranhão. Santo Antonio de Goiás, EMBRAPA Arroz e Feijão, Boletim de Pesquisa, 42p.

Lara F M (1991) Princípios de resistência de plantas aos insetos. 2 ed. São Paulo, Ícone, 336p. 
Moreira G R, Silva D J H, Picanço M C, Peternelli L A, Caliman F R B (2005) Divergência genética entre acessos de tomateiro infestados por diferentes populações da traça-do-tomateiro. Hort Bras 23: 893-898.

Pereira J J, Cruz C D (2003) Comparação de métodos de agrupamento para o estudo da diversidade genética de cultivares de arroz. Rev Ceres 287: 41-60.

Scott A J, Knott M A (1974) A cluster analysis method for grouping means in the analysis of variance. Biometrics 3: 507-512.

Suinaga F A, Casali V W D, Silva D J H, Picanço M C (2003) Dissimilaridade genética de fontes de resistência de Lycopersicon spp. a Tuta absoluta (Meyrick, 1917) (Lepidoptera: Gelechiidae). Rev Bras Agroc 9: 371-376.

Trujillo M R (1970) Contribuição ao conhecimento do dano e biologia de Tibraca limbativentris Stal, 1860 (HemipteraPentatomidae) praga da cultura do arroz. Dissertação de Mestrado. Escola Superior de Agricultura Luiz de Queiroz, Piracicaba, 63p.

Received 14/IV/08. Accepted 13/VII/09. 